\title{
Good family doctors are made not born: An overview of teaching and learning about professionalism in family medicine
}

John Yaphe*

A re good family doctors born or made? Can we teach the knowledge, skills and attitudes necessary to become a professional, proficient family doctor? There is much that we do not know about how this happens or how to make this happen. The reader is invited to reflect on the growing body of literature on teaching, learning, assessing and evaluating the effects of professionalism in medicine. It is worth exploring this challenging issue.

We have a hard time defining professionalism in medicine, let alone teaching or assessing it effectively. Family medicine has many definitions that are bound up in culture, tradition and history and there is no one accepted definition.

The European definition of general practice adopted by WONCA ${ }^{1}$ provides an important first step in understanding professionalism as does the EURACT educational agenda ${ }^{2}$ that was based on this definition. There are many items in the definition and the agenda that relate to the knowledge behaviour and attitudes of family doctors that can be fused into a definition of professionalism.

What is good family medicine and who is a good family doctor? That is one way to begin reflection on the nature of professionalism. There is a long list of attributes of good medicine and good doctors with general agreement on these items.

A profession is a vocation with a body of knowledge and skills put into service for the good of others, usually characterized by self-regulation. ${ }^{3}$ There are many defini-

*Dr. John Yaphe, Associate Professor, Community Health, School of Health Sciences, University of Minho, Braga, Portugal tions of professionalism used by the bodies charged with the responsibility of training doctors, namely faculties of medicine. For example, the Northeastern Ohio Universities College of Medicine sees professionalism as reliability and responsibility, honesty and integrity, maturity, respect for others, altruism, interpersonal skills, and the absence of impairment either psychological or chemical (as in alcoholism or drug abuse). The definition from the University of California at San Francisco includes a commitment to self-improvement and adaptability, excellent relationships with patients and families and with other members of the health care team.

If we look closely at these items, we will see that there are five clusters of professionalism in medicine. ${ }^{4}$ These are: adherence to ethical practice principles, effective interactions with patients and families, effective interactions with people working within the health system, reliability, and commitment to autonomous improvement of competence in oneself, others, and health care systems.

Many of these definitions were developed by expert bodies creating mission statement, by surveys or by a Delphi process. It has been possible to test these criteria using case vignettes. ${ }^{5}$ When presented with cases illustrating lapses in professional behaviour such as a lack of accountability, tardiness, lapses in excellence, inappropriate dress, laziness, dishonesty, disrespect, and impairment, physicians are generally in agreement. However there may be wide variation in scores for any item, independent of age, gender or stage of training. These finding suggest there is much work to be done in achieving agreement on the elements of professionalism. 
There are good reasons for this lack of agreement because the nature of professionalism changes as society changes as Sean Hilton has observed. ${ }^{6}$ The values of trust, competence, ethical practice, integrity, honesty, altruism and vocation remain unchanged. Other professional values such as internal self regulation have moved to accountability and openness. The former value of mastery of knowledge has changed to a credo of continuing professional development. There have been major changes from paternalism to partnership and mutuality, from tribalism to collegiality and from self-sacrifice to shared responsibility. The changes all require modifications in the medical curriculum to prepare new doctors for a changed society and a changed profession.

How then do we teach the new professionalism in medical schools? By 1999, over $90 \%$ of medical schools in the US had some formal teaching about professionalism in the curriculum. ${ }^{7}$ There are rites of passage such as the white coat ceremony or the swearing of oaths. Most medical schools teach the subordination of one's self interests, adherence to high ethical and moral standards, response to societal needs, and demonstration of evincible core humanistic values. Learning the "healer's art" includes the development of the person. This topic requires new methods such as small group learning and reflection and new attitudes to relationship-centered care to promote their development in students. ${ }^{8}$

Episodes of television medical dramas such as "Gray's Anatomy" have also been used to teach doctor-patient communication and inter-professional communication. ${ }^{9}$

Guided reflection on critical incidents witnessed during training may be used to teach students about professionalism. Troubling events experienced in the clinic can be turned into formative moments in the careers of some students. ${ }^{10}$

There are many methods used for assessing professionalism. Each of these methods possesses particular strengths and combination of methods can produce a valid and reliable measure of professionalism. For example critical incident reports made by faculty regarding student behaviour with timely feedback can result in remedial actions and improvement in professional behaviour. ${ }^{11}$ Peer assessment has also shown students to be keen and frank observers of their colleagues with regard to self-directed learning, interpersonal relationships and responsibility. ${ }^{12}$ Self-assessment by trainees with regard to interpersonal relations and conveying information to patients has also been shown to be an effective method..$^{13}$

In conclusion, professionalism can be defined, taught and assessed. While reflection by faculty on individual attitudes and local needs is of value, there is also a rich body of published literature available to help medical schools and training programs create an effective and relevant curriculum in education for professionalism.

(This editorial is based on a lecture presented to the $20^{\text {th }}$ international Bled course for teachers of Family Medicine held in Slovenia in September 2011. It was published in a modified format in Družinska Medicina 2011; 9 (Suppl 4): 103-107 and is reprinted here with the permission of the Slovene Society of Family Medicine.)

\section{CONFLICT OF INTEREST}

None

\section{REFERENCES}

1. The European Definition of General Practice/Family Medicine, WONCA Europe 2005. Policy Paper, Working Group from WONCA Europe and EURACT, http://www.euract.eu/official-documents/finish/3-official-documents/94-european-definition-of-general-practicefamily-medicine-2005-full-version (last accessed 11 September 2011).

2. Heyrman J, ed. EURACT Educational Agenda, European Academy of Teachers in General Practice EURACT, Leuven 2005. http://www.euract.eu/official-documents/finish/3-official-documents/93-euract-educational-agenda (last accessed 11 September 2011)

3. Arnold L. Assessing professional behavior: yesterday, today, and tomorrow. Acad Med 2002 Jun; 77 (6): 502-15.

4. Wilkinson TJ, Wade WB, Knock LD. A blueprint to assess professionalism: results of a systematic review. Acad Med 2009 May; 84 (5): 551-8.

5. Borrero S, McGinnis KA, McNeil M, Frank J, Conigliaro RL. Professionalism in residency training: is there a generation gap?. Teach Learn Med 2008 Jan-Mar; 20 (1): 11-7.

6. Hilton S. Education and the changing face of medical professionalism: from priest to mountain guide? Br J Gen Pract 2008 May; 58 (550): 353-61.

7. Swick HM, Szenas $P$, Danoff $D$, Whitcomb ME. Teaching professionalism in undergraduate medical education. JAMA 1999 Sep 1; 282 (9): 830-2.

8. Daaleman TP, Kinghorn WA, Newton WP, Meadorkg. Rethinking professionalism in medical education through formation. Fam Med 2011 May; 43 (5): 325-9.

9. Pavlov A, Dahlquist GE. Teaching communication and professionalism using a popular medical drama. Fam Med 2010 Jan; 42 (1): 25-7.

10. Stark P, Roberts $C$, Newble D, Bax N. Discovering professionalism through guided reflection Med Teach 2006 Feb; 28 (1): e25-e31.

11. Hodges D, McLachlan JC, Finn GM. Exploring reflective 'critical incident' documentation of professionalism lapses in a medical undergraduate setting. BMC Med Educ 2009 Jul 15; 9: 44.

12. Kovach RA, Resch DS, Verhulst SJ. Peer assessment of professionalism: a five-year experience in medical clerkship. J Gen Intern Med 2009 Jun: 24 (6): 742-6.

13. Symons AB, Swanson A, McGuigan D, Orrange S, Akl EA. A tool for self-assessment of communication skills and professionalism in residents. BMC Med Educ $2009 \operatorname{Jan} 8 ; 9: 1$.

ENDEREÇO PARA CORRESPONDÊNCIA

yonahyaphe@hotmail.com 